\title{
Impact of on-site cardiac catheterization on resource utilization and fatal and non-fatal outcomes after acute myocardial infarction Abdul R Halabi ${ }^{\dagger 1}$, Christine A Beck ${ }^{\dagger 2}$, Mark J Eisenberg ${ }^{\dagger 3}$, Hugues Richard ${ }^{\dagger 2}$ and Louise Pilote*+2
}

Address: ${ }^{1}$ Divisions of Cardiology, Montreal General Hospital, McGill University Health Center, Montreal, Canada, ${ }^{2}$ Clinical Epidemiology, Montreal General Hospital, McGill University Health Centre, Montreal, Canada and ${ }^{3}$ Divisions of Cardiology and Clinical Epidemiology, Jewish General Hospital, Montreal, Canada

Email: Abdul R Halabi - abdul.halabi@duke.edu; Christine A Beck - cabeck@dal.ca; Mark J Eisenberg - meisenberg@epid.jgh.mcgill.ca; Hugues Richard - Hugues@epimgh.mcgill.ca; Louise Pilote* - louise.pilote@mcgill.ca

* Corresponding author †Equal contributors

Published: 10 November 2006

BMC Health Services Research 2006, 6: 148 doi: I0.1 |86/1472-6963-6-148
Received: 28 March 2006

Accepted: 10 November 2006

This article is available from: http://www.biomedcentral.com//472-6963/6//48

(c) 2006 Halabi et al; licensee BioMed Central Ltd.

This is an Open Access article distributed under the terms of the Creative Commons Attribution License (http://creativecommons.org/licenses/by/2.0), which permits unrestricted use, distribution, and reproduction in any medium, provided the original work is properly cited.

\begin{abstract}
Background: Patterns of care for acute myocardial infarction (AMI) strongly depend on the availability of on-site cardiac catheterization facilities. Although the management found at hospitals without on-site catheterization does not lead to increased mortality, little it known about its impact on resource utilization and non-fatal outcomes.
\end{abstract}

Methods: We identified all patients $(n=35,289)$ admitted with a first AMl in the province of Quebec between January I, 1996 and March 3I, 1999 using population-based administrative databases. Medical resource utilization and non-fatal and fatal outcomes were compared among patients admitted to hospitals with and without on-site cardiac catheterization facilities.

Results: Cardiac catheterization and $\mathrm{PCl}$ were more frequently performed among patients admitted to hospitals with catheterization facilities. However, non-invasive procedures were not used more frequently at hospitals without catheterization facilities. To the contrary, echocardiography [odds ratio (OR), 2.04; 95\% confidence interval (Cl), I.93-2.16] and multi-gated acquisition imaging (OR, I.24; $95 \% \mathrm{Cl}, \mathrm{I.17}-1.32)$ were used more frequently at hospitals with catheterization, and exercise treadmill testing (OR, I.02; $95 \% \mathrm{Cl}, 0.9 \mathrm{I}-\mathrm{I.I5}$ ) and Sestamibi/ Thallium imaging (OR, $0.93 ; 95 \% \mathrm{Cl}, 0.88-0.98)$ were used similarly at hospitals with and without catheterization. Use of anti-ischemic medications and frequency of emergency room and physician visits, were similar at both types of institutions. Readmission rates for AMI-related cardiac complications and mortality were also similar [adjusted hazard ratio, recurrent AMI: $1.02,95 \% \mathrm{Cl}$, 0.89-I.16; congestive heart failure: 1.02 ; $95 \% \mathrm{Cl}, 0.90-1.15$; unstable angina: $0.93 ; 95 \% \mathrm{Cl}, 0.85-$ I.02; mortality: 0.99; 95\% Cl, 0.93-1.05)].

Conclusion: Although on-site availability of cardiac catheterization facilities is associated with greater use of invasive cardiac procedures, non-availability of catheterization did not translate into a higher use of non-invasive tests or have an impact on the fatal and non-fatal outcomes available for study in our administrative database. 


\section{Background}

Advances in pharmacological therapy and mechanical revascularization have markedly contributed to improved outcomes following acute myocardial infarction (AMI). However, practice variations persist with respect to the use of these treatment strategies. One factor known to contribute to this variation is the regionalization of facilities for invasive cardiac procedures. Strong, positive associations between the use of invasive cardiac procedures and the presence of on-site cardiac catheterization facilities have been established [1-9].

Several clinical trials and observational studies have suggested that a more invasive approach to management of AMI - as is found at hospitals with on-site cardiac catheterization facilities - is not associated with improved survival for all patient subgroups $[2-4,6,7,10-17]$. Thus, it is possible that the benefit of a universally applied invasive approach may not be commensurate with its substantial use of resources. However, it is also possible that there are aspects of a more selectively invasive approach - as is found at hospitals without on-site cardiac catheterization - that drive resource utilization, such as the use of noninvasive procedures after AMI.

We sought to determine how availability of on-site cardiac catheterization facilities at the hospital of admission for AMI might influence resource utilization, as well as fatal and non-fatal outcomes after AMI. We hypothesized that non-availability of cardiac catheterization facilities might translate into a higher use of non-invasive cardiac procedures, given the need to perform cardiac risk stratification. We also hypothesized that a lower use of invasive cardiac procedures might impact on the use of anti-ischemic medications, emergency room and outpatient physician visits, readmissions for AMI-related complications and mortality.

\section{Methods}

\section{Study Population}

A cohort of AMI patients was constructed from the universal hospital discharge summary database for the province of Quebec, Canada. We identified all patients admitted with a discharge diagnosis of AMI [International Classification of Diseases (ICD), $9^{\text {th }}$ revision code 410 ] between January $1^{\text {st }} 1996$ and March $31^{\text {st }} 1999(\mathrm{n}=40,857)$. The positive predictive value for coding an AMI for elderly patients in the database has been evaluated to be $96 \%$ (95\% CI, 94-98) [18]. In order to increase comparability and include patients based on only first episodes of AMI, we excluded patients who had a previous diagnosis of AMI between 1988 and 1995 (9.3\%). Additional patients were excluded if they were admitted to non-cardiac surgical units, or if the total length of stay (including transfers) for their admission was less than three days, because AMI is unlikely to be the primary diagnosis for such patients. Following these exclusions, our study population consisted of 35,289 patients (total exclusions were $13.6 \%$ of the original cohort). This method to identify AMI patients has been used extensively in Quebec [19], Ontario [20], and the United States [21].

Using encrypted Quebec Medicare numbers, we further linked the discharge summary database with the physician and drug claims database for the province of Quebec. These databases contain information on all diagnostic and therapeutic procedures in Quebec. They also contain information on resource use, such as outpatient physician visits and outpatient prescriptions filled. Due to the characteristics of the Quebec health care and health insurance systems, information on prescriptions was limited to patients 65 years of age and older.

Mortality data were obtained by merging data from several different sources: the hospital discharge summary database, institutions that manage pensions, government human resources and car insurance, and provincial death certificates. The algorithm we created using these different sources of information allowed us to determine the vital status for close to $100 \%$ of the study patients. All patients were followed from the date of their initial admission until December 31, 1999.

\section{Hospital Groups}

Study patients were grouped based on whether their admitting hospital had on-site cardiac catheterization facilities. A total of 16 hospitals had on-site cardiac catheterization facilities over the study period, and there were no changes in availability of catheterization at each of these hospitals over the study period. However, the number of hospitals without cardiac catheterization facilities changed over time, as there were some hospital closures between 1996 and 1999. Over these years, 100 to 116 hospitals were hospitals without cardiac catheterization facilities. Patients were classified according to whether or not they were initially admitted for AMI at hospitals with or without cardiac catheterization facilities. If a patient was initially admitted to a hospital without catheterization, and then transferred to a hospital with catheterization, the patient was "assigned" to the initial hospital without catheterization only.

\section{Medical Care Utilization}

For each patient, we obtained data on all in- and outpatient invasive and non-invasive cardiac procedures performed during the follow-up period. The invasive procedures studied were cardiac catheterization, percutaneous coronary intervention (PCI), and coronary artery bypass graft surgery (CABG). The non-invasive procedures studied were exercise treadmill testing, transthoracic 
echocardiography, and nuclear cardiac imaging [multigated acquisition (MUGA), Thallium/Sestamibi]. We examined cumulative incidence of all these procedures during the initial hospital admission for AMI, as well as at 1 year following the date of the initial admission for AMI. We also examined rates of primary $\mathrm{PCI}$, which was defined as receipt of PCI on the day of admission for AMI. In addition, we determined the median waiting period (time in days) between the date of the initial admission and any invasive cardiac procedure received within 1 year.

We also obtained data on prescriptions for medications with anti-ischemic properties, as well as frequency of emergency room and physician visits. The anti-ischemic medications studied were beta-blockers, nitrates and calcium channel blockers. We measured the cumulative incidence of prescriptions filled at 30 days post-discharge. We also measured the cumulative incidence of anti-ischemic combination therapy for the patients who were alive at 1 year post-discharge. Anti-ischemic combination therapy was defined as prescription for one (monotherapy), two (double therapy) or three (triple therapy) agents among beta-blockers, nitrates, and calcium channel blockers at 1 year post-discharge.

The frequencies of emergency room and outpatient physician visits during the year following discharge were also measured. All emergency room visits were included in analyses, irrespective of the reason for consultation. Outpatient physician visits included visits to internists, cardiologists, and family physicians.

\section{Readmissions and Mortality}

Readmission rates for cardiac-specific diagnoses examined were recurrent AMI (ICD-9 code 410), unstable angina (ICD-9 code 411,413,414) and congestive heart failure (ICD-9 code 428). Specifically, we measured cumulative incidence of readmission for these diagnoses at 30 days and 1 year following the date of discharge. Consistent with previous studies using similar administrative databases [8], we excluded any elective readmissions for invasive cardiac procedures.

Finally, cumulative incidence of mortality was measured during the initial hospitalization and at 30 days and 1 year after admission.

\section{Statistical Analysis}

We compared demographic and clinical characteristics, use of cardiac procedures and medications, frequency of emergency room and physician visits, and readmission and mortality rates for patients initially admitted for AMI at hospitals with and without on-site cardiac catheterization facilities. We then used multivariable Cox's proportional hazards models to estimate the association between admission at hospitals with and without cardiac catheterization facilities and the study outcomes. Assumptions of proportionality for the Cox models were verified for each study outcome. The models adjusted for age at admission, sex, the interaction between age at admission and sex, the year of admission, co-morbid illnesses (diabetes mellitus, chronic obstructive pulmonary disease, cerebrovascular disease, malignancy, congestive heart failure, renal failure, peripheral vascular disease), shock, specialty of the treating physician (cardiologist or not), university affiliation of hospital of admission, and AMI patient volume of hospital of admission (low, medium or high volume). The study was approved by the institutional review board at the McGill University, Montreal, Canada.

\section{Results \\ Patient Characteristics}

Among the 35,289 study patients, 9,355 (27\%) were admitted to hospitals with on-site cardiac catheterization facilities. Patients admitted to both types of hospitals had similar demographic and clinical characteristics, but different hospital characteristics (Table 1). For example, patients admitted to hospitals with cardiac catheterization facilities were more likely to be treated by cardiologists, to be admitted to a university-affiliated hospital and a highvolume (>100 AMI admissions/year) hospital. Finally, median length of stay was shorter for patients admitted to hospitals with cardiac catheterization facilities.

\section{Invasive Cardiac Procedures}

Invasive cardiac procedures were performed in a higher proportion of patients admitted to hospitals with cardiac catheterization facilities (Table 2). Catheterization was used more frequently in-hospital [odds ratio (OR), 4.00; $95 \%$ confidence interval (CI), 3.78-4.24] and at 1 year (OR, 1.76; 95\% CI, 1.68-1.85). Similarly, PCI was used more frequently in-hospital (OR, 6.20; 95\% CI, 5.70$6.74)$ and at 1 year (OR, 1.98; 95\% CI, 1.86-2.09). Primary PCI (among patients with catheterization) was also used more frequently (OR, 41.8; 95\% CI, 32.2-54.3). Rates of CABG were slightly higher for patients admitted to hospitals with cardiac catheterization facilities in-hospital (OR, 1.91; 95\% CI, 1.48-2.45), but modestly lower at 1 year (OR, $0.86 ; 95 \% \mathrm{CI}, 0.78-0.94)$.

Waiting periods between admission and procedures were shorter for patients admitted to hospitals with cardiac catheterization facilities. However, for those patients who required CABG following catheterization, there was no difference in the waiting period from catheterization to CABG in both types of hospitals.

\section{Non-invasive Cardiac Procedures}

Overall, non-invasive cardiac procedures were not used more frequently at hospitals without on-site availability 
Table I: Patient and hospital characteristics, according to availability of on-site cardiac catheterization facilities at the hospital of admission for acute myocardial infarction

\begin{tabular}{|c|c|c|}
\hline & $\begin{array}{l}\text { Hospitals with Catheterization Facilities } \\
\qquad(n=9,355)\end{array}$ & $\begin{array}{l}\text { Hospitals without Catheterization Facilities } \\
\qquad(n=25,934)\end{array}$ \\
\hline \multicolumn{3}{|l|}{ Patient characteristic (\%) } \\
\hline Median age, years (IQR) & $67(55-76)$ & $67(55-76)$ \\
\hline Patients $>65$ years & 56.2 & 56.3 \\
\hline Male & 65.4 & 64.9 \\
\hline Hypertension & 35.0 & 28.8 \\
\hline Diabetes mellitus & 22.0 & 19.9 \\
\hline Dyslipidemia & 20.9 & 17.8 \\
\hline Heart failure & 21.7 & 22.1 \\
\hline Atrial fibrillation & 9.9 & 8.7 \\
\hline Chronic obstructive pulmonary disease & 12.2 & 15.2 \\
\hline Peripheral vascular disease & 8.5 & 7.8 \\
\hline Cerebrovascular disease & 6.8 & 6.4 \\
\hline Chronic renal failure & 7.3 & 5.7 \\
\hline Acute renal failure & 4.8 & 4.6 \\
\hline Shock & 5.7 & 4.7 \\
\hline Malignancy & 2.1 & 2.3 \\
\hline \multicolumn{3}{|l|}{ Hospital characteristic (\%) } \\
\hline Median length of stay, days (IQR) & $7(5-12)$ & $9(6-14)$ \\
\hline \multicolumn{3}{|l|}{ Treating physician specialty } \\
\hline Cardiology & 92.4 & 28.9 \\
\hline Family medicine & 2.8 & 57.7 \\
\hline Internal medicine & 2.3 & 12.4 \\
\hline University-affiliation & 86.9 & 33.6 \\
\hline \multicolumn{3}{|l|}{ AMI patient volume } \\
\hline$<50$ cases AMI/year & 0 & 1.2 \\
\hline 50-100 cases AMI/year & 0 & 17.2 \\
\hline > 100 cases AMI/year & 100.0 & 81.6 \\
\hline
\end{tabular}

IQR denotes interquartile range, AMI denotes acute myocardial infarction.

of cardiac catheterization facilities (Table 2). To the contrary, echocardiography was used more frequently in hospitals with cardiac catheterization facilities in-hospital (OR, 2.56; 95\% CI, 2.43-2.69) and at 1 year (OR, 2.04; 95\% CI, 1.93-2.16). Similarly, MUGA imaging was used more frequently in-hospital (OR, 1.32; 95\% CI, 1.221.42 ) and at 1 year (OR, 1.24; 95\% CI, 1.17-1.32). In contrast, exercise treadmill testing was used similarly in both groups (OR at 1 year, 1.02; 95\% CI, 0.91-1.15) and Sestamibi/Thallium imaging was used only slightly less frequently at hospitals with cardiac catheterization facilities (OR at 1 year, 0.93; 95\% CI, 0.88-0.98).

\section{Anti-Ischemic Prescriptions, Emergency Room and Physician Visits}

There were no significant differences in rates of prescriptions for cardiac medications at 30 days post-discharge between the two groups (Table 3). Refill rates for sublingual nitrates were also comparable in both groups, as were rates of prescription for anti-ischemic combination therapy at 1 year (Table 3 ). Furthermore, the total number of emergency room and physician visits was similar in both groups at 1 year post-discharge.

\section{Readmissions and Mortality}

We found similar rates of readmission for recurrent AMI and congestive heart failure at 30 days and 1 year post-discharge in both groups [recurrent AMI and congestive heart failure adjusted hazard ratio (HR), 1.02; 95\% CI, 0.891.16 and $\mathrm{HR}, 1.02$; 95\% CI, 0.90-1.1), respectively] (Table 4). There was no difference in readmission rates for unstable angina (HR, 0.93; 95\% CI, 0.85-1.02).

Mortality rates were also similar for patients admitted to hospitals with and without cardiac catheterization facilities in-hospital (9\% versus $10 \%$ ), at 30 days (13\% versus $14 \%$ ), and 1 year (20\% versus $21 \%$ ). In addition, adjusted rates were similar for the entire follow-up period (adjusted HR, 0.99; 95\% CI, 0.93-1.05) (Figure 1). Finally, because mortality is very high in patients with shock and there was a higher proportion of patients with shock at hospitals with on-site catheterization, we per- 
Table 2: Cumulative incidence of invasive and non-invasive cardiac procedures

\begin{tabular}{|c|c|c|}
\hline & $\begin{array}{l}\text { Hospitals with Catheterization Facilities } \\
\qquad(n=9,355)\end{array}$ & $\begin{array}{l}\text { Hospitals without Catheterization Facilities } \\
\qquad(n=25,934)\end{array}$ \\
\hline \multicolumn{3}{|c|}{ Non-invasive procedures (\%) } \\
\hline \multicolumn{3}{|c|}{ Exercise treadmill test $*$} \\
\hline In-hospital & 27.2 & 24.0 \\
\hline I year & 48.2 & 47.5 \\
\hline \multicolumn{3}{|l|}{ Echocardiogram } \\
\hline In-hospital & 66.7 & 44.0 \\
\hline I year & 76.2 & 61.0 \\
\hline \multicolumn{3}{|l|}{ MUGA scan } \\
\hline In-hospital & 11.0 & 8.6 \\
\hline I year & 23.9 & 20.1 \\
\hline \multicolumn{3}{|c|}{ Thallium/Sestamibi scan } \\
\hline In-hospital & 8.3 & 6.0 \\
\hline I year & 23.8 & 25.2 \\
\hline \multicolumn{3}{|c|}{ Invasive procedures (\%) } \\
\hline \multicolumn{3}{|c|}{ Catheterization } \\
\hline In-hospital & 35.1 & 11.9 \\
\hline I year & 51.2 & 37.3 \\
\hline \multicolumn{3}{|l|}{$\mathrm{PCl}$} \\
\hline Primary $\mathrm{PCl}$ & 9.0 & 0.2 \\
\hline In-hospital & 18.5 & 3.5 \\
\hline I year & 28.2 & 16.6 \\
\hline \multicolumn{3}{|l|}{ CABG } \\
\hline In-hospital & 1.1 & 0.6 \\
\hline I year & 8.2 & 9.4 \\
\hline
\end{tabular}

MUGA denotes multi-gated acquisition, $\mathrm{PCl}$ denotes percutaneous coronary intervention, CABG denotes coronary artery bypass graft surgery.

*Data available only for patients admitted from June I, I998-1999 $(n=8,74 I)$.

formed a model that excluded patients with shock and failed to find a mortality difference (adjusted HR, 1.0; 95\% CI, 0.94-1.07).

In univariate analysis, the effect of physicians specialty, hospital teaching status and volume appeared to also greatly affect the various outcomes that were measures (Table 4). However, the effect of on-site catheterization availability remained the same after addition of these variables to our multivariate models. The relationship between on-site catheterization and mortality and cardiac readmissions is thus unexplained by these other variables. However, in multivariate analysis, cardiologists appears to be associated with better outcomes independent of being admitted to a hospital with on-site catheterization and, in particular, with fewer readmissions for unstable angina [adjusted HR, recurrent AMI: 0.97; 95\% CI, 0.86-1.08; congestive heart failure: $0.92 ; 95 \% \mathrm{CI}, 0.83-1.03$; unstable angina: $0.90 ; 95 \% \mathrm{CI}, 0.83-0.98$; mortality: $0.93 ; 95 \%$ CI, 0.88-0.98].

\section{Discussion}

Lack of availability of on-site cardiac catheterization facilities did not result in an increased use of non-invasive test- ing for risk stratification following AMI. In contrast, despite a higher rate of use of in-hospital catheterization (and presumably left ventriculography), ventricular assessment via echocardiography and MUGA imaging was used more frequently for patients admitted at hospitals with catheterization facilities. Lower use and longer waiting times for invasive cardiac procedures at hospitals without catheterization facilities did not result in worse clinical outcomes. Use of anti-ischemic medications, frequency of emergency room and outpatient physician visits, and rates of readmission for AMI-related cardiac complications and mortality were unaffected by catheterization availability.

The association between availability and use of on-site cardiac catheterization facilities has been well documented $[2,3]$. Furthermore, the management strategy of routine cardiac catheterization following AMI has been shown not to impact on mortality, but few studies have assessed the impact of this strategy on outcomes such as non-fatal outcomes and utilization of medical resources. A reduction in readmissions for unstable angina was shown in the Thrombolysis In Myocardial Infarction (TIMI) III-B trial, thus slightly favoring the "early inva- 
Table 3: Cardiac prescriptions, physicians and emergency room visits post-discharge after acute myocardial infarction

\begin{tabular}{|c|c|c|}
\hline & $\begin{array}{l}\text { Hospitals with Catheterization Facilities } \\
\qquad(n=4,116)\end{array}$ & $\begin{array}{c}\text { Hospitals without Catheterization } \\
\text { Facilities }(\mathrm{n}=\mathrm{I}, 1,190)\end{array}$ \\
\hline \multicolumn{3}{|l|}{ Medication class* (\%) } \\
\hline Aspirin & 65.4 & 64.2 \\
\hline Beta-blockers & 57.7 & 52.6 \\
\hline ACE inhibitors & 45.2 & 44.0 \\
\hline Nitrates (any form) & 72.7 & 73.0 \\
\hline Calcium channel blockers & 27.6 & 28.1 \\
\hline Lipid-lowering agents & 24.9 & 20.8 \\
\hline \multicolumn{3}{|c|}{ Anti-ischemic combination therapy at I yeart (\%) } \\
\hline Monotherapy & 38.8 & 41.6 \\
\hline Double therapy & 27.3 & 27.9 \\
\hline Triple therapy & 7.8 & 7.2 \\
\hline Refills for sublingual nitrates at I year (\%) & 31.4 & 28.7 \\
\hline \multicolumn{3}{|l|}{ Emergency room visits at I year (\%) } \\
\hline 0 visits & 43.3 & 43.3 \\
\hline $\mathrm{I}-3$ visits & 41.4 & 41.3 \\
\hline$\leq 4$ visits & 15.4 & 15.4 \\
\hline \multicolumn{3}{|l|}{ Physician visits at I year (\%) } \\
\hline $0-3$ visits & 22.3 & 18.9 \\
\hline $4-8$ visits & 38.5 & 39.7 \\
\hline$\leq 9$ visits & 39.2 & 41.4 \\
\hline
\end{tabular}

ACE denotes angiotensin-converting enzyme.

* For patients $\leq 65$ years of age only; $\dagger$ Anti-ischemic combination therapy was defined as prescription for one (monotherapy), two (double therapy) or three (triple therapy) agents among beta-blockers, nitrates, and calcium channel blockers at six months post-discharge (for patients $\leq 65$ years of age only, $n=15,306)$.

Table 4: Effect of catheterization availability, physician specialty, university affiliation and volume on fatal and non-fatal outcome

\begin{tabular}{|c|c|c|c|c|}
\hline & \multicolumn{4}{|c|}{ Hazard Ratios and $\mathbf{9 5} \%$ Confidence Intervals } \\
\hline & $\begin{array}{c}\text { Catheterization } \\
\text { Availability }\end{array}$ & Physician Specialty* & University Affiliation & Volume $>=150$ \\
\hline \multicolumn{5}{|c|}{$\begin{array}{l}\text { Congestive Heart } \\
\text { Failure }\end{array}$} \\
\hline Unadjusted & $1.01(0.92-1.12)$ & $0.85(0.78-0.92)$ & $1.03(0.94-1.12)$ & $0.97(0.88-1.06)$ \\
\hline Adjusted & $1.02(0.90-1.15)$ & $0.92(0.83-1.03)$ & $1.07(0.96-1.19)$ & $0.94(0.85-1.05)$ \\
\hline \multicolumn{5}{|c|}{ Unstable Angina } \\
\hline Unadjusted & $0.81(0.76-0.87)$ & $0.82(0.77-0.87)$ & $0.91(0.86-0.97)$ & $0.758(0.7 \mathrm{I}-0.8 \mathrm{I})$ \\
\hline Adjusted & $0.93(0.85-1.02)$ & $0.90(0.83-0.98)$ & $1.11(1.03-1.19)$ & $0.80(0.74-0.86)$ \\
\hline \multicolumn{5}{|c|}{ Recurrent AMI } \\
\hline Unadjusted & $0.97(0.87-1.07)$ & $0.90(0.83-0.99)$ & $0.92(0.84-1.01)$ & $0.93(0.84-1.03)$ \\
\hline Adjusted & $1.02(0.89-1.16)$ & $0.97(0.86-1.08)$ & $0.92(0.83-1.03)$ & $0.95(0.85-1.06)$ \\
\hline \multicolumn{5}{|l|}{ Mortality } \\
\hline Unadjusted & $0.98(0.94-1.03)$ & $0.84(0.81-0.88)$ & $1.02(0.98-1.06)$ & $1.05(1.00-1.10)$ \\
\hline Adjusted & $0.99(0.93-1.05)$ & $0.93(0.88-0.98)$ & $1.02(0.97-1.07)$ & $1.08(1.03-1.14)$ \\
\hline
\end{tabular}

* Cardiologists compared to internists or family physicians.

Note: The adjusted relative risks need to be interpreted with caution because variables are highly correlated. 


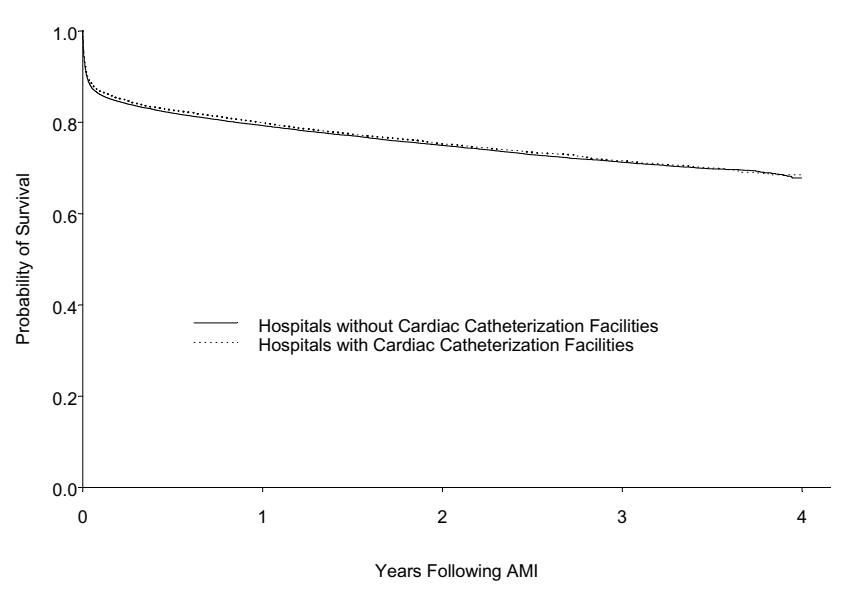

Figure I

Probability of survival among patients with acute myocardial infarction admitted at sites with and without cardiac catheterization facilities.

sive" approach [15]. More recently, the Treat Angina with Aggrastat and Determine Cost of Therapy with an Invasive or Conservative Strategy-Thrombolysis In Myocardial Infarction 18 (TACTICS-TIMI 18) investigators reported a lower incidence of major cardiac events with the use of an "early invasive" strategy combined with glycoprotein IIb/ IIIa inhibition [22]. Whereas the TIMI-IIIB and TACTICS trials prospectively examined the incidence of cardiac events following unstable angina and AMI, few investigators have used large administrative databases to examine non-fatal outcomes and resource utilization with a population-based approach. Our study extends these previous studies by providing new information, at the population level, for a large number of patients from a recent cohort. This type of analysis is complementary to that of the clinical trials, as it is relevant to the "real world" care of patients in several jurisdictions where the routine application of the invasive approach is not feasible. However, given the overall relatively infrequent use of the invasive approach in both study groups, this study cannot provide a valid comparison of a routine invasive versus non-invasive approach. Instead, it provides evidence that certain outcomes are similar for patients treated at hospitals with more versus less selective use of invasive cardiac procedures, albeit at an overall still highly selective level. The overall equivalence for other important endpoints, such as outpatient burden of angina and heart failure symptoms, remains indeterminate.

Only one other study has recently used administrative data to examine such a hypothesis [8]. Alter et al. found that the non-fatal composite 5-year event rate was lower when patients were admitted to hospitals with cardiac catheterization facilities from 1992 to 1993 . Unlike Alter et al., we did not find an effect of availability of cardiac catheterization facilities on rates of readmissions for unstable angina. However, only $11 \%$ of patients in the study by Alter et al. were initially admitted to hospitals with cardiac catheterization facilities, suggesting that lower readmission rates for angina may have been related to elective admissions for invasive cardiac procedures. Our results regarding cardiac readmissions reflect a more recent trend of practice.

In order to identify the interplay between physician specialty, university affiliation, volume of AMI admissions and on-site availability of cardiac catheterization facilities, we included all these variables in our multivariate models. There appears to be little confounding bias by physician specialty, hospital teaching status and hospital volume of AMI admissions. We could not identify any apparent benefit of being treated at hospitals with cardiac catheterization facilities, despite the more prevalent use of invasive cardiac procedures, the shorter waiting periods for revascularization, the greater proportion of patients treated by cardiologists, university-affiliations, and the higher volume of AMI admissions. However, our multivariate regression estimates should be interpreted with caution due to their high correlation with availability of on-site cardiac catheterization.

Our study presented the following limitations. First, while we adjusted for several important patient-, physician- and hospital-related characteristics in our multivariate analyses, our administrative databases do not contain information on in-hospital pharmacological treatment including thrombolytic therapy or detailed clinical characteristics that could confound our analyses. However, the similarities in available clinical characteristics across the two groups provide a good indication that more detailed clinical characteristics would also be similar. Findings from a previous study using detailed chart review data support this claim. Second, it was difficult to assess the role of the treating physician and the teaching status and volume of the admitting hospital in relationship with catheterization laboratory availability because these variables are highly correlated. The difficulty to abstract collinear variables in such analyses represents an important challenge in this field. Finally, there is the possibility for some misclassification bias in our databases. For example, a readmission diagnosis of unstable angina may actually reflect an elective admission for pre-planned cardiac catheterization. As in previous studies, we excluded all readmissions where catheterization was performed on the same or next day following admission. In fact, few patients were excluded under this criterion; we repeated analyses with and without these exclusions and found comparable readmission rates. 


\section{Conclusion}

In conclusion, the lower use of invasive cardiac procedures at hospitals without on-site catheterization did not translate into a higher use of non-invasive tests. Furthermore, use of anti-ischemic cardiac medications, emergency room visits, outpatient physician visits, readmissions for AMI-related complications and mortality were similar at each type of hospital.

\section{Competing interests}

The author(s) declare that they have no competing interests.

\section{Authors' contributions}

AH drafted the manuscript. CB assisted with the literature review and editing of the manuscript, as well as the statistical analyses. HR performed the statistical analyses. ME and LP conceived of the study and obtained the study data. All authors participated in the design and coordination of the study, and read and approved the final manuscript.

\section{Acknowledgements \\ None}

\section{References}

I. Pilote L, Miller D, Califf R, Rao J, Weaver W, Topol E: Determinants of the use of coronary angiography and revascularization after thrombolysis for acute myocardial infarction in the United States. N Engl J Med 1996, 335: I I98-I205.

2. Every N, Larson E, Litwin P, Maynard C, Fihn SD, Eisenberg MS, Hallstrom AP, Martin JS, Weaver D, for The Myocardial Infarction Triage and Intervention Project Investigators: The association between on-site cardiac catheterization facilities and the utilization of coronary angiography after acute myocardial infarction. $N$ Engl I Med 1993, 329:546-551.

3. Behark S, Hod H, Benari B, Narinsky R, Pauzner H, Rechavia E, Faibe HE, Katz A, Roth A, Goldhammer E, Freedberg NA, Rougin N, Kracoff O, Shapira C, Jafari J, Lotan C, Daka F, Gottlieb S, Weiss T, Kanetti M, Klutstein M, Rudnik L, Barasch E, Mahul N, Blondheim D, Gelvan A, Barbash G: On-site catheterization laboratory and prognosis after acute myocardial infarction. Arch Intern Med 1995, I 55:813-817.

4. Wright SM, Daley J, Peterson ED, Thibault GE, Outcomes of acute myocardial infarction in the Department of Veterans Affairs: Does regionalization of health care work? Med Care 1997, 35: $128-14 \mid$.

5. Every NR, Parsons LS, Fihn SD, Larson EB, Maynard C, Hallstrom AP, Martin JS, Weaver D: Long-term outcome in acute myocardia infarction patients admitted to hospitals with and without on-site cardiac catheterization facilities. Circulation 1997 96: $1770-1775$.

6. Krumholz HM, Chen J, Murillo JE, Cohen DJ, Radford MJ: Admission to hospitals with on-site cardiac catheterization facilities. Impact on long-term costs and outcomes. Circulation 1998 , 98:2010-2016

7. Rogers WJ, Canto JG, Barron HV, Boscarino JA, Shoultz DA, Every NR: Treatment and outcome of myocardial infarction in hospitals with and without invasive capability. I Am Coll Cardiol 2000, 35:37|-379.

8. Alter DA, Naylor CD, Austin PC, Tu JV: Long-term MI outcomes at hospitals with or without on-site revascularization. JAMA 200I, 285:2101-2108.

9. Yusuf S, Flather M, Pogue J, Hunt D, Varigos J, Piegas L, Avezum A Anderson J, Keltai M, Budaj A, Fox K, Ceremuynski L, for the OASIS (Organisation to assess strategies for iscaemic syndromes) registry investigators: Variations between countries in invasive cardiac procedures and outcomes in patients with suspected unstable angina or myocardial infarction without initial ST elevation. Lancet 1998, 352:507-5I4.

10. Simoons M, Arnold A, Betriu A, De Buono DP, Col J, Dougherty FC von Essen R, Lambertz H, Lubsen J, Meier B, et al:: Thrombolysis with tissue plasminogen activator in acute myocardial infarction: no additional benefit from immediate percutaneous coronary angioplasty. Lancet 1988, I:197-203.

II. Rogers WJ, Baim DS, Gore JM, Brown BG, Roberts R, Williams DO, Chesebro JH, Babb JD, Sheehan FH, Wackers FJT, Zaret BL, Robertson TL, Passamani ER, Ross R, Knatterud GL, Braunwald E: Comparison of immediate invasive, delayed invasive and conservative strategies after tissue-type plasminogen activator results of the Thrombolysis In Myocardial Infarction (TIMI) Phase II-A Trial. Circulation 1990, 8I:|457-|476.

12. SWIFT Trial Study Group: SWIFT trial of delayed elective intervention vs conservative treatment after thrombolysis with anistreplase in acute myocardial infarction. $\mathrm{Br}$ Med J 1991, 302:555-560.

13. Williams D, Braunwald E, Knatterud G, Babb J, Bresnahan J, Greenberg MA, Raizner A, Wasserman A, Robertson T, Ross R: One-year results of the Thrombolysis in Myocardial Infarction Investigation (TIMI) Phase II trial. Circulation 1992, 85:533-542.

14. Barbash GI, Roth A, Hod H, Modan M, Miller HI, Rath S, Zahav YH, Keren G, Motro M, Shachar A, Basan S, Agranat O, Rabinowitz B, Laniado S, Kaplinsky E: Randomized controlled trial of late inhospital angiography and angioplasty versus conservative management after treatment with recombinant tissue-type plasminogen activator in acute myocardial infarction. Am J Cardiol 1990, 66:538-545.

15. Anderson H, Cannon C, Stone P, Williams D, McCabe C, Knatterud $\mathrm{G}$, Thompson B, Willerson J, Braunwald E, for the TIMI IIIB investigators: One-year results of the thrombolysis in myocardial infarction (TIMI IIIB) clinical trial. I Am Coll Cardiol 1995, 26: $1643-1650$.

16. Boden W, O'Rourke R, Crawford M, Blausten A, Deedwania P, Zoble R, Wexler L, Kleiger R, Pepine C, Ferry D, Chow B, Lavori P, for the Veterans Affairs Non-Q Wave Infarction Strategies in Hospital (VANQWISH) Trial investigators: Outcomes in patients with acute non- $Q$ wave myocardial infarction randomly assigned to an invasive as compared with a conservative management strategy. N Engl J Med I998, 338: I785-1792.

17. Wallentin L, Lagerqvist B, Husted S, Kontny F, Stahle E, Swahn E: Outcome at $I$ year after an invasive compared with a noninvasive strategy in unstable coronary-artery disease: the FRISC II invasive randomised trial. The Lancet 2000, 356:9-16.

18. Levy AR, Tamblyn RM, Fitchett D, McLeod PJ, Hanley JA: Coding accuracy of hospital discharge data for elderly survivors of myocardial infarction. Can J Cardiol 1999, I 5: I277- I 282.

19. Pilote L, Lavoie F, Ho V, Eisenberg M: Changes in the treatment and outcomes of acute myocardial infarction in Quebec, 1988-1995. Can Med Assoc J 2000, I 63:31-36.

20. Tu JV, Naylor D, Austin P: Temporal changes in the outcomes of acute myocardial infarction in Ontario, 1992-1996. Can Med Assoc J 1999, 16 1:1257-1261.

21. Udvarhelyi IS, Gatsonis C, Epstein AM, Pashos CL, Newhouse JP, McNeil B]: Acute myocardial infarction in the Medicare population. Process of care and clinical outcomes. JAMA I992, 268:2530-2536.

22. Cannon CP, Weintraub WS, Demopoulos LA, Vicari R, Frey MJ, Lakkis N, Neumann F-J, Robertson DH, DeLucca PT, DiBattiste PM, Gibson $M$, Braunwald $E$ : Comparison of early invasive and conservative strategies in patients with unstable coronary syndromes treated with the glycoprotein IIb/IIla inhibitor tirofiban. N Engl J Med 200I, 344:1879-1887.

\section{Pre-publication history}

The pre-publication history for this paper can be accessed here:

\section{http://www.biomedcentral.com/1472-6963/6/148/pre} pub 